\section{Essential role of BCL9-2 in the switch between $\beta$-catenin's adhesive and transcriptional functions}

\author{
Felix H. Brembeck, ${ }^{1}$ Thomas Schwarz-Romond, ${ }^{1,3}$ \\ Jeroen Bakkers, ${ }^{2,4}$ Sabine Wilhelm, ${ }^{1}$ \\ Matthias Hammerschmidt, ${ }^{2}$ and \\ Walter Birchmeier ${ }^{1,5}$ \\ ${ }^{1}$ Max Delbrueck Center for Molecular Medicine, 13092 Berlin, \\ Germany; ${ }^{2}$ Max Planck Institute for Immunobiology, \\ 79108 Freiburg, Germany
}

$\beta-C a t e n i n$ controls both cadherin-mediated cell adhesion and activation of Wnt target genes. We demonstrate here that the $\beta$-catenin-binding protein BCL9-2, a homo$\log$ of the human proto-oncogene product BCL9, induces epithelial-mesenchymal transitions of nontransformed cells and increases $\beta$-catenin-dependent transcription. RNA interference of BCL9-2 in carcinoma cells induces an epithelial phenotype and translocates $\beta$-catenin from the nucleus to the cell membrane. The switch between $\beta$-catenin's adhesive and transcriptional functions is modulated by phosphorylation of Tyr 142 of $\beta$-catenin, which favors BCL9-2 binding and precludes interaction with $\alpha$-catenin. During zebrafish embryogenesis, BCL9-2 acts in the Wnt8-signaling pathway and regulates mesoderm patterning.

Received May 27, 2004; revised version accepted July 20, 2004.

Wnt/ $\beta$-catenin signals act in concert with other signaling systems to control patterning in early, and organogenesis in late stages of development (De Robertis et al. 2000; Huelsken and Birchmeier 2001; Moon et al. 2002). In the adult, deregulated Wnt $/ \beta$-catenin signaling can cause tumors (Bienz and Clevers 2000). In the presence of Wnt signals, cytoplasmically located $\beta$-catenin is stabilized and interacts with transcription factors of the Lef/ Tcf family to control nuclear transcription (Behrens et al. 1996; Korinek et al. 1997; Eastman and Grosschedl 1999). $\beta$-Catenin also functions in cell adhesion at the plasma membrane, where it connects cadherins to $\alpha$-catenin and the cytoskeleton (Takeichi 1995). The molecular mechanism of the switch between the adhesive and transcriptional functions of $\beta$-catenin was unknown.

In B-cell lymphomas, chromosomal translocations can activate proto-oncogenes (Rowley 2001). The t(1;14)(q21;q32)

[Keywords: BCL9/legless; $\alpha$-catenin; Wnt8; tyrosine phosphorylation; epithelial-mesenchymal transition; mesoderm patterning]

Present addresses: ${ }^{3}$ Medical Research Council Laboratory of Molecular Biology, Hills Road, CB2 2QH, Cambridge, UK; ${ }^{4}$ Hubrecht Laboratorium, Uppsalalaan $8,3584 \mathrm{CT}$ Utrecht, Netherland.

${ }^{5}$ Corresponding author.

E-MAIL wbirch@mdc-berlin.de; FAX 49-30-94062656.

Article published online ahead of print. Article and publication date are at http://www.genesdev.org/cgi/doi/10.1101/gad.317604. translocation uncovered the BCL9 gene, and caused BCL9 overexpression in the tumors (Willis et al. 1998). Recently legless, the Drosophila ortholog of BCL9, was found to act as a segment polarity gene and to function in the Wnt/ $\beta$-catenin pathway in cooperation with pygopus (Kramps et al. 2002; Thompson et al. 2002). The role of BCL9 proteins in vertebrate development and tumor progression had not been determined.

\section{Results and Discussion}

Vertebrate BCL9-2 proteins show an overall amino acid sequence identity of $60 \%$, and $35 \%$ identity to the human proto-oncogene product BCL9 (Fig. 1A; see GenBank AY296057 to AY296061; Willis et al. 1998). Up to $90 \%$ sequence identity was found in seven short clusters of 20-30 amino acids, which are also conserved in legless from Drosophila (this study; Kramps et al. 2002): the $\beta$-catenin-binding domain ( $\beta$-catBD), the pygopus (PyBD)binding domain, a domain that contains a classical nuclear localization signal (NLS, KRRK motif), three Cterminal homology domains (C-HD1 to C-HD3), and a novel $\mathrm{N}$-terminal homology domain (N-HD) that contains a lysine-rich potential sumoylation motif $\left(\mathrm{K}^{\star} \mathrm{K}^{\star} \mathrm{KXE} / \mathrm{D}\right.$; in amino acid residues 108-137; Melchior 2000) and a sequence similar to classical nuclear localization signals (PRSKRRC; in amino acids 138-173; Hicks and Raikhel 1995).

\section{BCL9-2 in nontransformed cells induces epithelial-mesenchymal transition, nuclear translocation of $\beta$-catenin, and increases cell migration}

We expressed BCL9-2 in epithelial MDCK cells and established cell clones that had stably incorporated the expression vector. Control cells formed round compact colonies at subconfluency, and exhibited the typical cobblestone morphology of epithelial cells (Fig. 1B, top left). In contrast, BCL9-2 expressing colonies were flattened and irregularly shaped, and contained scattered cells (Fig. 1B, bottom left). Moreover, BCL9-2 expressing colonies were completely scattered in the presence of suboptimal dosages of Hepatocyte Growth Factor (HGF; Fig. 1B, bottom, middle, and right), which activates the receptor tyrosine kinase Met (Birchmeier et al. 2003). Control clones were not scattered at these low concentrations of HGF (Fig. 1B, top, middle, and right). BCL92-expressing cells also exhibited a threefold increased cell migration, as observed in Transwell cultures (data not shown). These results suggest that BCL9-2 induces epithelial-mesenchymal transitions, and that tyrosine phosphorylation by Met collaborates with BCL9-2 action.

Epithelial-mesenchymal transitions correlated with complex formation of BCL9-2 and $\beta$-catenin in the nucleus of the scattered cells; BCL9-2 was located in the nucleus (the nucleoli were excluded) and translocated $\beta$-catenin to the nuclear compartment (Fig. 1C, bottom), whereas $\beta$-catenin located at the plasma membrane, but not in the nucleus in control cells (Fig. 1C, top). A fragment of BCL9-2 that contains only the N-terminal domain (amino acids 1-175) also located to the nucleus (Fig. 1D, left). In contrast, BCL9-2 with a deletion of the 


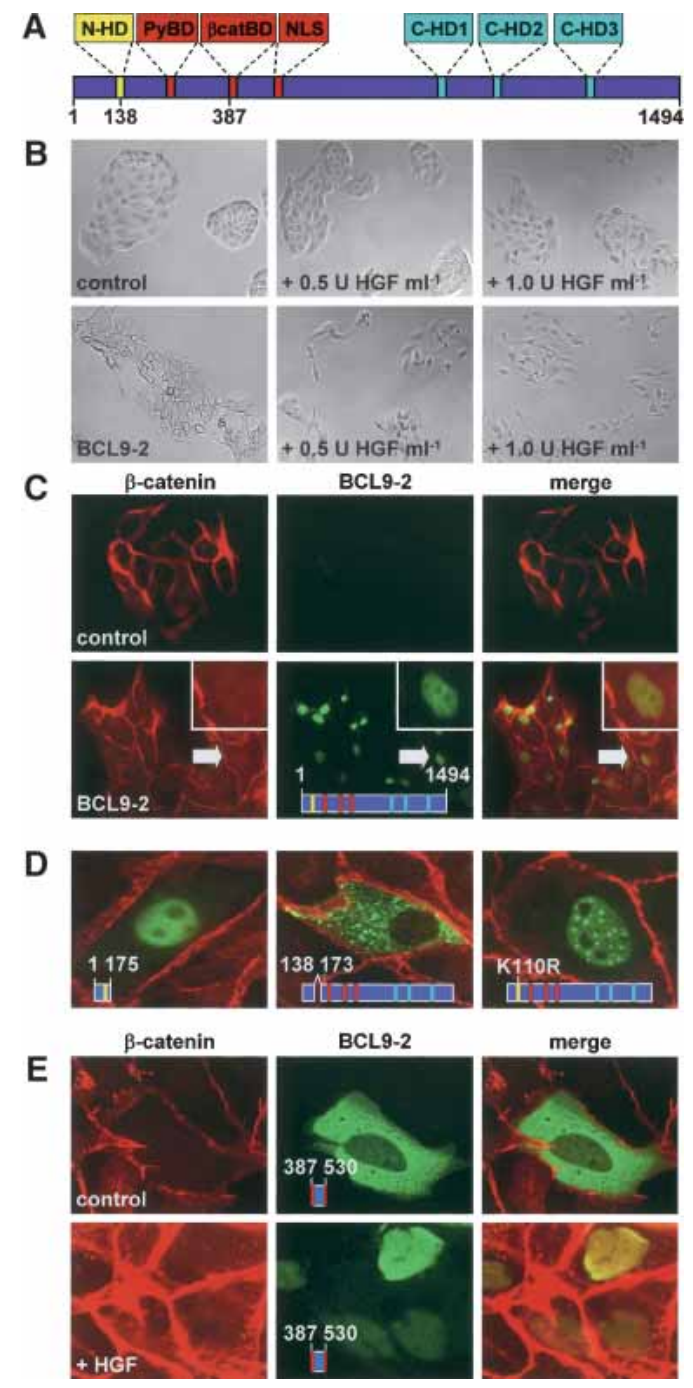

Figure 1. BCL9-2 induces epithelial-mesenchymal transition and nuclear translocation of $\beta$-catenin in MDCK cells. (A) Domain structure of the vertebrate BCL9-2 protein. The seven conserved domains are highlighted; positions of amino acids are indicated. $(B)$ Morphology of BCL9-2-transfected MDCK cells and controls. HGF treatment was for $18 \mathrm{~h} .(\mathrm{C})$ Immunofluorescence microscopy of MDCK cells for endogenous $\beta$-catenin (red), transfected BCL9-2 (green), and merged fluorescence (yellow). Arrows mark $\beta$-catenin collocation with BCL9-2 (see also inset). (D) Cellular localization of deletions and point mutants of BCL9-2. (E) Localization of the isolated $\beta$-catenin-binding fragment of BCL9-2 (amino acids 387-530) in MDCK cells. Treatment with $2 \mathrm{U} \mathrm{mL}^{-1} \mathrm{HGF}$ was for $6 \mathrm{~h}$. The used BCL9-2 constructs are schematically indicated in the figures.

nuclear localization signal of the $\mathrm{N}$-terminal domain ( $\Delta$ amino acids 138-173) was located in the cytoplasm (Fig. 1D, middle). Mutations of the putative sumoylation motif in the N-terminal domain of BCL9-2 (e.g., the K110R mutation) favored accumulation in nuclear bodies (Fig. 1D, right). The BCL9/legless homologs, which lack the nuclear localization signal in the N-terminal domain, did not localize to the nucleus (data not shown; see also Townsley et al. 2004).

Tyrosine phosphorylation of $\beta$-catenin also contributed to nuclear translocation, a deletion fragment of BCL9-2 that contained only the $\beta$-catenin-binding domain (amino acids 387-530) located to the cytoplasm
(Fig. 1E, top). Upon HGF treatment, $\beta$-catenin was partially released from the plasma membrane, translocated to the nucleus, where it colocalized with the BCL9-2 fragment (Fig. 1E, bottom).

\section{RNA interference of BCL9-2 in transformed cells induces reversion to the epithelial phenotype and translocates $\beta$-catenin from the nucleus to the plasma membrane}

We used colon cancer cell lines that exhibit activated Wnt/ $\beta$-catenin signaling by mutation of the tumor suppressor gene APC (Behrens et al. 1998). SW480 cells are fibroblast-like and show high levels of nuclear $\beta$-catenin (Fig. 2B, top), and they express high levels of BCL9-2 (Fig. 2A). Transfection with specific siRNAs against BCL9-2
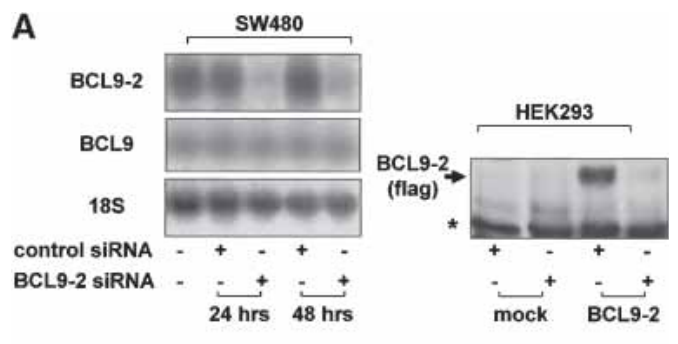

B
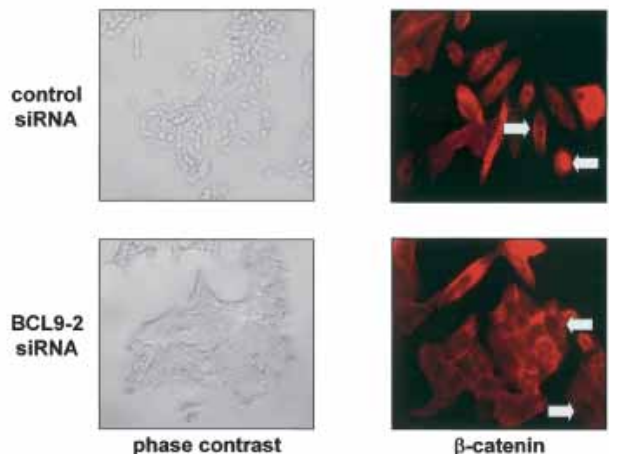

C
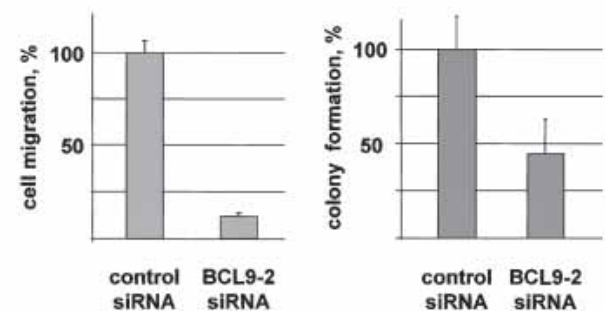

Figure 2. RNA interference of BCL9-2 in transformed cells reverts cells to the epithelial phenotype, translocates $\beta$-catenin from the nucleus to the plasma membrane, and reverts transformed properties. $(A$, left $)$ Northern blot of SW480 cells that were transfected with BCL9-2 siRNAs or controls for 24 and $48 \mathrm{~h}$. The used probes are indicated on the left. (Right) Western blot of nuclear extracts of HEK293 cells that were stably transfected with BCL9-2 or control vector, and treated for $96 \mathrm{~h}$ with BCL9-2 siRNAs. (B) Morphology and immunofluorescence of endogenous $\beta$-catenin of SW480 cells that were transfected with BCL9-2 siRNAs or controls for $72 \mathrm{~h} .(C$, left) Cell migration of SW480 cells that were treated with BCL9-2 siRNAs or controls for $72 \mathrm{~h}$. The number of migrating cells (from three independent transfections) is expressed as percent of control cells. (Right) Colony formation of DLD-1 cells that were treated with BCL9-2 siRNAs or controls for $72 \mathrm{~h}$. Colonies in soft agar (from three independent transfections) were counted after $10 \mathrm{~d}$ and expressed as percent of controls. 
A
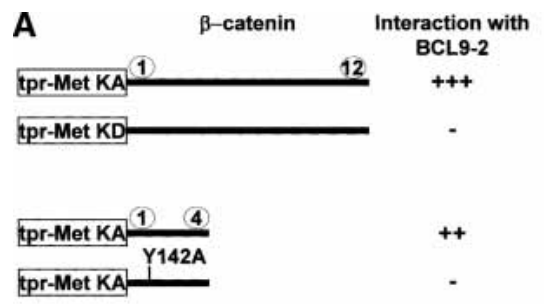

B

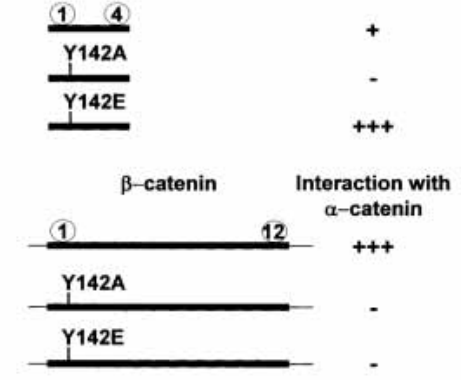

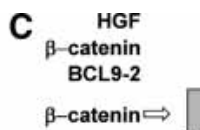

$+$
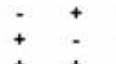

IP:

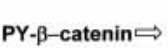

WB

anti-BCL9-2 (HA)

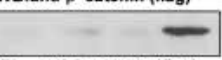

$\beta$-catenin $\Rightarrow$

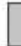

BCL9-2 $\Rightarrow$

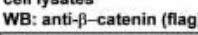
cell lysates

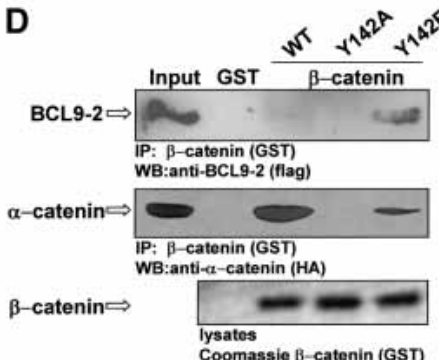

Figure 3. Phosphorylation of Tyr 142 of $\beta$-catenin mediates complex formation with BCL9- 2 and reduces $\alpha$-catenin binding. $(A)$ Interaction of tpr-Met- $\beta$-catenin fusion proteins, of $\beta$-catenin repeats $1-4$, and Y142 mutations thereof with BCL9-2 (amino acids 387-530), as determined by yeast two-hybrid assays. Arm repeats of $\beta$-catenin are depicted by numbers. (KA) kinase-active; (KD) kinase-defective fusion proteins. (B) Interaction of $\beta$-catenin and Y142 mutations thereof with $\alpha$-catenin. Note that constructs without tpr-met were in the prey, BCL9-2 in the bait vectors. Interactions (+ or - ) were quantified by growth of yeast on selective medium and by $\beta$-galactosidase activity in solution. $(C)$ Interaction of BCL9-2 and tyrosine-phosphorylated $\beta$-catenin in COS-7 cells in response to HGF treatment $\left(5 \mathrm{U} \mathrm{mL}^{-1}\right.$ for 18 $\mathrm{h}$ ), as determined by coimmunoprecipitation. BCL9-2 (amino acids 387-530) was cotransfected with full-length $\beta$-catenin. $(D)$ Interaction of BCL9-2 and $\alpha$-catenin with wild-type and Y142 mutant $\beta$-catenin, as determined by GST- $\beta$-catenin pulldown experiments. BCL9-2 (amino acids 387-530) and full size $\alpha$-catenin were prepared from transfected COS-7 cells.

reduced endogenous BCL9-2 (but not BCL9) RNA levels almost completely within $24 \mathrm{~h}$, and abolished protein expression of transfected BCL9-2 in HEK293 cells (Fig. 2A). Remarkably, the morphology of the BCL9-2 siRNAs-treated SW480 cells became epithelial-like, and $\beta$-catenin was translocated from the nucleus to the cell membrane (Fig. 2B, bottom). Moreover, cell migration of the treated SW480 cells was drastically reduced (Fig. 2C, left). BCL9-2 siRNA's treatment of DLD-1 colon cancer cells also induced loss of nuclear $\beta$-catenin, and the cells showed reduced colony formation in soft agar (Fig. 2C, right; data not shown).

\section{Tyrosine phosphorylation of $\beta$-catenin controls complex formation with BCL9-2}

We initially identified BCL9-2 as an interaction partner of tyrosine-phosphorylated $\beta$-catenin in a yeast two-hybrid screen. BCL9-2 interacted efficiently with $\beta$-catenin in yeast when the armadillo domains were fused to kinase-active, but not to kinase-defective Met (Fig. 3A; see also Fujita et al. 2002 for construction of yeast baits). Armadillo repeats 1 and 2 of $\beta$-catenin are required to bind BCL9-2, which contain only one tyrosine residue at position 142. Mutation of Y142 to alanine indeed abro- gated BCL9-2 binding, whereas mutation to glutamic acid (Y142E), which can mimic tyrosine phosphorylation, increased binding efficiency (Fig. 3A).

The presence of a nonphosphorylated Tyr 142 in $\beta$-catenin is required for $\alpha$-catenin binding (Aberle et al. 1996; Pokutta and Weis 2000). The mutations Y142A and Y142E both abrogated binding to $\alpha$-catenin (Fig. 3B). Interaction of BCL9-2 with tyrosine-phosphorylated $\beta$-catenin was confirmed by coimmunoprecipitation from tissue culture cells. HGF treatment of cells induced tyrosine phosphorylation of $\beta$-catenin and promoted interaction with BCL9-2 (Fig. 3C), as did the Y142E mutation of $\beta$-catenin in GST pull-down experiments (Fig. 3D). In contrast, a strongly reduced binding between $\beta$-catenin and $\alpha$-catenin was observed when the Y142A and Y142E mutations were present in $\beta$-catenin.

\section{BCL9-2 promotes $\beta$-catenin's transcriptional activity that is enhanced by tyrosine phosphorylation}

We used HEK293 cells, which contain low levels of endogenous BCL9-2 and $\beta$-catenin (data not shown), for testing the transcriptional activity of BCL9-2. Full-size BCL9-2 enhanced $\beta$-catenin-dependent transcription threefold (Fig. 4A). BCL9-2 had no effect in the absence of $\beta$-catenin. Moreover, mutation of the conserved lysines in the potential sumoylation motif of the $\mathrm{N}$-terminal domain of BCL9-2 (K108R, K110R, or K112R) activated $\beta$ catenin-dependent transcription up to ninefold (Fig. 4A; data not shown). Remarkably, expression of the BCL9-2 fragment that contains the $\beta$-catenin-binding domain only (amino acids 387-530) and does not affect binding of $\beta$-catenin to Lef/Tcfs abolished $\beta$-catenin-dependent transcription (Fig. 4A; data not shown). Deletion of the nuclear localization signal in the $\mathrm{N}$-terminal domain of BCL9-2 ( $\Delta$ amino acids 138-173) abolished transcriptional activation. Internal deletion of the previously identified pygopus-binding domain of BCL9 proteins showed that this domain is not required in BCL9-2 to potentiate $\beta$-catenin's transcriptional activity (data not shown). BCL9/legless stimulated transcription to a similar degree, but this activation was dependent on the pygopus-binding domain (data not shown; see also Townsley et al. 2004). BCL9-2 expression increased $\beta$-catenindependent transcription also in other assays, as assessed for the expression levels of the Wnt target gene conductin (data not shown; Lustig et al. 2002). BCL9-2 siRNA treatment of SW480 and DLD-1 cells significantly reduced transcriptional activity of $\beta$-catenin (Fig. 4B).The coactivator function of BCL9-2 depended on Y142 of $\beta$-catenin; in the presence of $\beta$-catenin that contains a Y142A mutation, BCL9-2 had a reduced effect on transcription (Fig. 4C, top). $\alpha$-Catenin blocked $\beta$-catenin's transcriptional activity (Fig. 4C; Giannini et al. 2000). This inhibition was overcome by cotransfected BCL9-2, but only in the presence of wild-type and not of Y142A mutant $\beta$-catenin (Fig. 4C, bottom). We also forced tyro- 

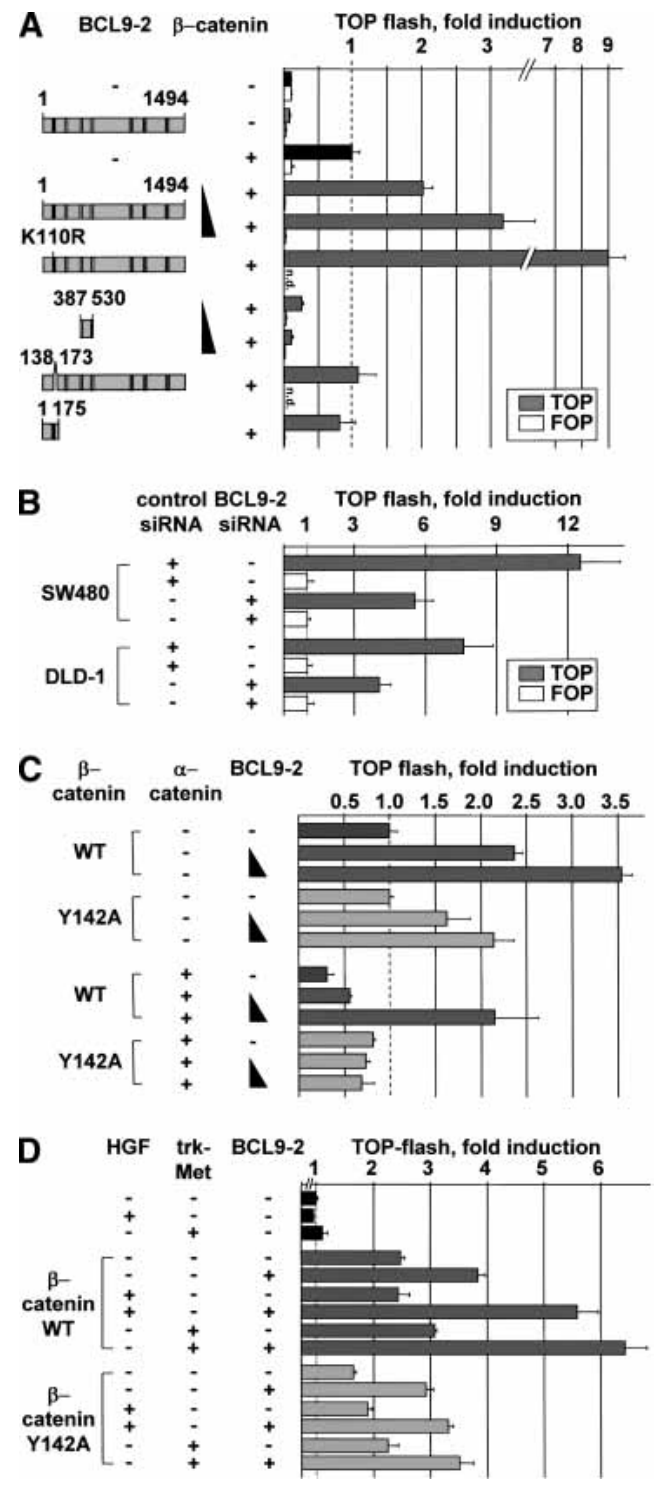

Figure 4. BCL9-2 is an essential nuclear coactivator of $\beta$-catenin signaling. $(A)$ Transcriptional activation of $\beta$-catenin and BCL9-2 in HEK293 cells. Deletions and mutants of BCL9-2 are shown schematically on the left. A total of $0.5 \mu \mathrm{g}$ of S33A $\beta$-catenin and 1.0-3.0 $\mu \mathrm{g}$ of BCL9-2 were cotransfected with the TOP (gray bars) or the control FOP reporter (open bars). (B) Transcriptional activation of $\beta$-catenin in SW480 and DLD-1 colon carcinoma cells that were treated with BCL9-2 siRNAs or controls for 48 and $72 \mathrm{~h}$. Transfection with the reporters was for another $24 \mathrm{~h}$. (C) Transcriptional activation in HEK293 cells of wild-type or Y142A mutant $\beta$-catenin, and effects of cotransfected BCL9-2 and $\alpha$-catenin; $0.5 \mu \mathrm{g} \beta$-catenin, $1.0 \mu \mathrm{g} \alpha$-catenin, and $0.25-1.0 \mu \mathrm{g}$ BCL9-2 were transfected. $(D)$ Transcriptional activation of $\beta$-catenin and the Y142A mutant in response to HGF treatment (50 $\mathrm{U} \mathrm{mL}^{-1}$ for $18 \mathrm{~h}$ ) or by cotransfected trk-Met $(0.15 \mu \mathrm{g}) ; 0.25 \mu \mathrm{g} \beta$-catenin and $3.0 \mu \mathrm{g}$ BCL9-2 were transfected. HEK293 cells were cultured at reduced serum concentrations (50\% DMEM and 50\% OptimemI, Invitrogen).

sine phosphorylation of $\beta$-catenin by HGF treatment of cells and by cotransfection of the receptor tyrosine kinase trk-Met (Fig. 4D; Schaeper et al. 2000). BCL9-2 cofactor function was increased, but only in the case of wild-type, and not Y142A mutant $\beta$-catenin (Fig. 4D).

\section{BCL9-2 controls mesoderm patterning in zebrafish embryogenesis}

In zebrafish embryos, BCL9-2 and BCL9 mRNAs are contributed maternally and are highly expressed during gastrulation (data not shown). Injection of antisense BCL9-2 morpholinos (MOs) into zebrafish embryos resulted in severe defects of trunk and tail developmental (Fig. 5A). BCL9-2 MOs directed against the start codon were highly effective at minimal dosages $(0.03$ pmole/embryo). The mutant phenotype was observed in $80 \%$ of the cases $(n=450)$. In contrast, different MOs against the homolog BCL9/legless had no effect $(n=375$; data not shown). Moreover, coinjection of BCL9-2 and BCL9 MOs did not alterate the developmental defects induced by BCL9-2 MOs alone ( $n=150$; data not shown). The lossof-function of BCL9-2 suggested a deficit in Wnt8 signaling (Erter et al. 2001; Lekven et al. 2001). At 70\% epiboly of wild-type embryos, floating head was expressed in the dorsal axial mesoderm, and tbx 6 in the ventro-lateral mesoderm. After injections of BCL9-2 MOs, the expression of floating head was broadened, and tbx6 expression was lost (Fig. 5B,C; data not shown). Moreover, injection of low concentrations of MOs against BCL9-2 and Wnt8 synergized to suppress tbx6 expression in the ventrolateral mesoderm (data not shown). No change of expression of pax 2.1 or otx 2 in the neuroectoderm was observed (data not shown). Loss of tbx6 expression induced by BCL9-2 MOs was completely rescued by mouse BCL9-2 mRNA, indicating that the MOs specifically target zebrafish BCL9-2 (Fig. 5D). Injection of mouse BCL9-2 mRNA alone expanded tbx6 expression (Fig. 5E). Injection of BCL9-2 mRNA that encodes a fragment lacking the $\mathrm{N}$-terminal domain did not expand tbx6 expression, nor did such injection rescue the phenotypes of

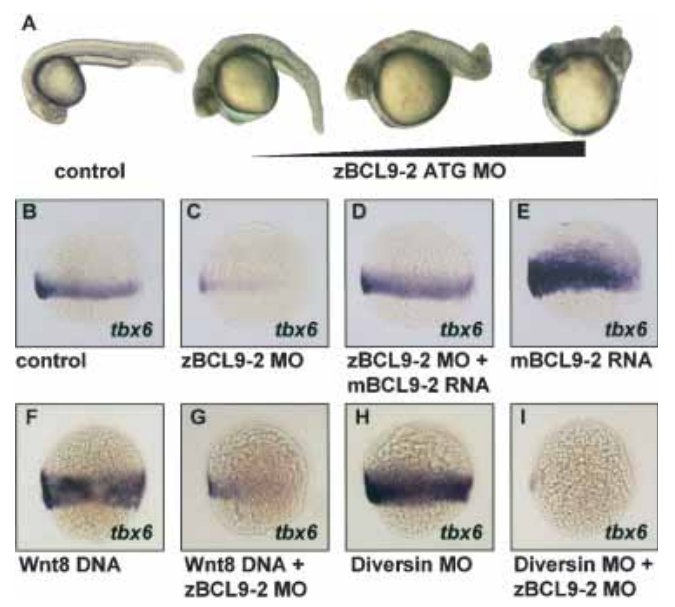

Figure 5. BCL9-2 in zebrafish embryos acts downstream in the Wnt8/B-catenin pathway to pattern the ventro-lateral mesoderm. (A) Malformations of trunk and tail in embryos treated with BCL9-2 ATG MOs at $26 \mathrm{~h}$ post-fertilization. Dependence on the amount of injected MOs. $(B-E)$ Effects of BCL9-2 MOs on the expression of the ventro-lateral mesoderm marker tbx6 at 70\% epiboly. BCL9-2 MOs $(0.03$ pmole; $C)$, BCL9-2 MOs in combination with mouse BCL9-2 RNA (1.5 ng; $D)$, and mBCL9-2 RNA alone $(E)$. Control is in $B .(F-I)$ Epistasis of the action of Wnt8, Diversin, and BCL9-2, as examined by expression of tbx6. Wnt8 DNA (0.06 ng; F), Diversin MOs $(0.6$ pmole; $H)$, and in combination with BCL9-2 MOs $(G, I)$. Lateral view, anterior up, dorsal to the right. 
BCL9-2 MOs (data not shown).We also examined the epistasic relationship between Wnt8, Diversin (a negative regulator of $\beta$-catenin signaling; Schwarz-Romond et al. 2002) and BCL9-2 in zebrafish embryos. Injection of Wnt8 DNA or stabilization of $\beta$-catenin by injection of Diversin MOs lead to an expansions of tbx6 expression (Fig. $5 \mathrm{~F}, \mathrm{H}$; an increase of tbx 6 by Wnt 8 in $100 \%, n=45$, and by Diversin MOs in $85 \%, n=52$ ). This was completely blocked by coinjection of BCL9-2 MOs (Fig. 5G,I; loss of tbx6 by Wnt 8 plus BCL9-2 MOs in $89 \%, n=39$, and by Diversin plus BCL9-2 MOs in $81 \%, n=33$ ).

Epithelial-mesenchymal transitions occur during critical phases of embryonic development. Such transitions are also observed late in the progression of carcinomas and provide a possible metastatic mechanism. Several signaling systems can induce epithelial-mesenchymal transitions, such as Wnt/ $\beta$-catenin, TGF $\beta /$ BMPs, or tyrosine kinases (Hay 1995; Thiery 2002; Birchmeier et al. 2003). Epithelial-mesenchymal transitions are initiated by a breakdown of the E-cadherin $/ \beta$ catenin $/ \alpha$-catenin complex at the plasma membrane and a dissociation of this adhesive complex from the cytoskeleton, which can be induced by tyrosine phosphorylation of $\beta$-catenin (Behrens et al. 1993; Fujita et al. 2002; Piedra et al. 2003). We demonstrate here that BCL9-2 forms a complex with $\beta$-catenin that is phosphorylated at Tyr 142, which precludes interaction with $\alpha$-catenin. Phosphorylation of Tyr 142 of $\beta$-catenin and interaction with BCL9-2 allows location of the complex in the nucleus and increases transcription of Wnt/ $\beta$-catenin target genes. Thus, BCL9-2 appears to contribute to oncogenicity by two mechanisms: (1) interfering with cadherins, which act as tumor suppressor genes (Birchmeier and Behrens 1994; Perl et al. 1998), and (2) by increased signaling of family members of the Wnt pathway, which contains many oncogenes and tumor suppressor genes (Bienz and Clevers 2000; Polakis 2000).

During vertebrate embryogenesis, Wnt/ $\beta$-catenin signals control formation of the dorso-anterior axis and patterning of the mesoderm at early, and organ specification at later stages of development (De Robertis et al. 2000; Huelsken and Birchmeier 2001; Moon et al. 2002). In zebrafish embryos, Wnt8/ $\beta$-catenin signaling is required to pattern ventro-lateral mesoderm and to posteriorize neural ectoderm (Erter et al. 2001; Lekven et al. 2001). We show here that BCL9-2, but not the homolog BCL9/ legless, is essential for mesoderm patterning in early zebrafish embryogenesis, and that BCL9-2 acts downstream of Wnt8/ $\beta$-catenin. However, BCL9-2 does not appear to be required for other early functions of the canonical Wnt pathway, such as formation of the dorsal organizer or posteriorization of anterior neuroectoderm (Kelly et al. 2000; Lekven et al. 2001). Our data therefore suggest that BCL9-2 acts as a specific modulator of canonical Wnt signaling at particular developmental stages, rather than as a general component of Wnt signaling.

\section{Materials and methods}

cDNAs of BCL9s were obtained by RT-PCR of total RNA from human HEK293 cells, mouse liver tissue, or zebrafish tailbud stage embryos. The 5 ' UTR of zebrafish BCL9-2 was produced by 5 'RACE (Clontech). Deletion constructs of mouse BCL9-2 and human $\beta$-catenin were generated by restriction enzyme digests and PCR amplification. The point mutations K108R, K110R, and K112R of BCL9-2, and of Y142 of $\beta$-catenin were generated by overlapping PCR mutagenesis.
Analysis of BCL9-2 function in cultured cells

Yeast two-hybrid screens were performed as described (Behrens et al. 1996; Schaeper et al. 2000). Tagged cDNA constructs were transfected in the indicated cell lines using Lipofectamine 2000 (Invitrogen), and protein expression was analyzed using anti-flag (Sigma), anti-HA (Roche), rabbit anti- $\beta$-catenin, and anti-PY20 antibodies as described (Behrens et al. 1996; Fujita et al. 2002). Immunofluorescence was detected with antiflag and anti- $\beta$-catenin antibodies, followed by Cy3- and Alexa Fluor 488-conjugated secondary antibodies (Jackson Immunoresearch and Molecular Probes). Transcriptional activity of $\beta$-catenin was measured as described (Korinek et al. 1997; Schwarz-Romond et al. 2002). Equal expression of the transfected BCL9-2 constructs was monitored by Western blotting. siRNAs against human BCL9-2 were obtained from Dharmacon, and $100 \mathrm{nM}$ of four pooled siRNAs were transfected using Lipofectamine 2000. The sequences were 5'-GAACAGCAGTGGCGTGATG-3', 5'-GCTGATGCCTTCACAGTTT-3', 5'-GACCTCACCATCAGTATTA-3', and $5^{\prime}$-CAGGCAACCTCAACATGAA-3'. Cell migration was determined in Transwell chambers (12-mm diameter, 12- $\mu \mathrm{m}$ pore size; Corning) with $5 \times 10^{4}$ cells, using a CellTiter-Glo assay (Promega). Colony formation was determined in a clonogenic assay with $1 \times 10^{3}$ cells, as described (Brembeck et al. 1998).

Analysis of BCL9-2 function in zebrafish embryos

Embryos from the AB-Strain were injected into the yolk at the one-tofour-cell stage, and in situ hybridizations were performed as described (Hammerschmidt et al. 1996; Nasevicius and Ekker 2000). Antisense MOs were obtained from Gene Tools. The BCL9-2 ATG MO was TG CATTTGATTGGCTGGTGATGGAG. Other MO sequences can be obtained upon request (brembeck@mdc-berlin.de). Sequences of Wnt8 $1+2$ and Diversin MOs were as published (Lekven et al. 2001; Schwarz-Romond et al. 2002).

\section{Acknowledgments}

We thank Drs. C. Birchmeier and U. Schaeper for helpful discussion and critical reading of the manuscript, and C. Köster (Freiburg) for excellent technical assistance. We are grateful to R.T. Moon (Seattle) for plasmids. This work was supported by grants from the DFG (SFB 366 to W.B.) and the NIH (1R01-GM63904 to M.H.).

\section{References}

Aberle, H., Schwartz, H., Hoschuetzky, H., and Kemler, R. 1996. Single amino acid substitutions in proteins of the armadillo gene family abolish their binding to $\alpha$-catenin. J. Biol. Chem. 271: 1520-1526.

Behrens, J., Vakaet, L., Friis, R., Winterhager, E., Van Roy, F., Mareel, M.M., and Birchmeier, W. 1993. Loss of epithelial differentiation and gain of invasiveness correlates with tyrosine phosphorylation of the E-cadherin/ $\beta$-catenin complex in cells transformed with a temperature-sensitive v-SRC gene. J. Cell Biol. 120: 757-766.

Behrens, J., von Kries, J.P., Kuhl, M., Bruhn, L., Wedlich, D., Grosschedl, R., and Birchmeier, W. 1996. Functional interaction of $\beta$-catenin with the transcription factor LEF-1. Nature 382: 638-642.

Behrens, J., Jerchow, B.A., Wurtele, M., Grimm, J., Asbrand, C., Wirtz, R., Kuhl, M., Wedlich, D., and Birchmeier, W. 1998. Functional interaction of an axin homolog, conductin, with $\beta$-catenin, APC, and GSK3ß. Science 280: 596-599.

Bienz, M. and Clevers, H. 2000. Linking colorectal cancer to Wnt signaling. Cell 103: 311-320.

Birchmeier, W. and Behrens, J. 1994. Cadherin expression in carcinomas: Role in the formation of cell junctions and the prevention of invasiveness. Biochim. Biophys. Acta 1198: 11-26.

Birchmeier, C., Birchmeier, W., Gherardi, E., and Vande Woude, G.F. 2003. Met, metastasis, motility and more. Nat. Rev. Mol. Cell Biol. 4: 915-925.

Brembeck, F.H., Kaiser, A., Detjen, K., Hotz, H., Foitzik, T., Buhr, H.J. Riecken, E.O., and Rosewicz, S. 1998. Retinoic acid receptor $\alpha$ mediates growth inhibition by retinoids in rat pancreatic carcinoma DSL-6A/C1 cells. Br. J. Cancer 78: 1288-1295.

De Robertis, E.M., Larrain, J., Oelgeschlager, M., and Wessely, O. 2000. The establishment of Spemann's organizer and patterning of the vertebrate embryo. Nat. Rev. Genet. 1: 171-181. 
Eastman, Q. and Grosschedl, R. 1999. Regulation of LEF-1/TCF transcription factors by Wnt and other signals. Curr. Opin. Cell Biol. 11: 233-240.

Erter, C.E., Wilm, T.P., Basler, N., Wright, C.V., and Solnica-Krezel, L. 2001. Wnt8 is required in lateral mesendodermal precursors for neural posteriorization in vivo. Development 128: 3571-3583.

Fujita, Y., Krause, G., Scheffner, M., Zechner, D., Leddy, H.E., Behrens, J., Sommer, T., and Birchmeier, W. 2002. Hakai, a c-Cbl-like protein, ubiquitinates and induces endocytosis of the E-cadherin complex. Nat. Cell Biol. 4: 222-231.

Giannini, A.L., Vivanco, M., and Kypta, R.M. 2000. $\alpha$-catenin inhibits $\beta$-catenin signaling by preventing formation of a $\beta$-catenin ${ }^{\star} \mathrm{T}$-cell factor ${ }^{\star}$ DNA complex. J. Biol. Chem. 275: 21883-21888.

Hammerschmidt, M., Pelegri, F., Mullins, M.C., Kane, D.A., Brand, M., van Eeden, F.J., Furutani-Seiki, M., Granato, M., Haffter, P., Heisenberg, C.P., et al. 1996. Mutations affecting morphogenesis during gastrulation and tail formation in the zebrafish, Danio rerio. Development 123: 143-151.

Hay, E.D. 1995. An overview of epithelio-mesenchymal transformation. Acta Anat. (Basel) 154: 8-20.

Hicks, G.R. and Raikhel, N.V. 1995. Protein import into the nucleus: An integrated view. Annu. Rev. Cell Dev. Biol. 11: 155-188.

Huelsken, J. and Birchmeier, W. 2001. New aspects of Wnt signaling pathways in higher vertebrates. Curr. Opin. Genet. Dev. 11:547-553.

Kelly, C., Chin, A.J., Leatherman, J.L., Kozlowski, D.J., and Weinberg, E.S. 2000. Maternally controlled $\beta$-catenin-mediated signaling is required for organizer formation in the zebrafish. Development 127: 3899-3911.

Korinek, V., Barker, N., Morin, P.J., van Wichen, D., de Weger, R., Kinzler, K.W., Vogelstein, B., and Clevers, H. 1997. Constitutive transcriptional activation by a $\beta$-catenin-Tcf complex in $\mathrm{APC}^{-/-}$colon carcinoma. Science 275: 1784-1787.

Kramps, T., Peter, O., Brunner, E., Nellen, D., Froesch, B., Chatterjee, S., Murone, M., Zullig, S., and Basler, K. 2002. Wnt/wingless signaling requires BCL9/legless-mediated recruitment of pygopus to the nuclear $\beta$-catenin-TCF complex. Cell 109: 47-60.

Lekven, A.C., Thorpe, C.J., Waxman, J.S., and Moon, R.T. 2001. Zebrafish wnt8 encodes two wnt8 proteins on a bicistronic transcript and is required for mesoderm and neurectoderm patterning. Dev. Cell 1: 103-114.

Lustig, B., Jerchow, B., Sachs, M., Weiler, S., Pietsch, T., Karsten, U., van de Wettering, M., Clevers, H., Schlag, P.M., Birchmeier, W., et al. 2002. Negative feedback loop of Wnt signaling through upregulation of conductin/axin2 in colorectal and liver tumors. Mol. Cell Biol. 22: 1184-1193.

Melchior, F. 2000. SUMO-nonclassical ubiquitin. Annu. Rev. Cell Dev. Biol. 16: 591-626.

Moon, R.T., Bowerman, B., Boutros, M., and Perrimon, N. 2002. The promise and perils of Wnt signaling through $\beta$-catenin. Science 296: 1644-1646.

Nasevicius, A. and Ekker, S.C. 2000. Effective targeted gene 'knockdown' in zebrafish. Nat. Genet. 26: 216-220.

Perl, A.K., Wilgenbus, P., Dahl, U., Semb, H., and Christofori, G.1998. A causal role for E-cadherin in the transition from adenoma to carcinoma. Nature 392: 190-193.

Piedra, J., Miravet, S., Castano, J., Palmer, H.G., Heisterkamp, N., Garcia de Herreros, A., and Dunach, M. 2003. p120 Catenin-associated Fer and Fyn tyrosine kinases regulate $\beta$-catenin Tyr-142 phosphorylation and $\beta$-catenin- $\alpha$-catenin interaction. Mol. Cell Biol. 23: 2287-2297.

Pokutta, S. and Weis, W.I. 2000. Structure of the dimerization and $\beta$-catenin-binding region of $\alpha$-catenin. Mol. Cell 5: 533-543.

Polakis, P. 2000. Wnt signaling and cancer. Genes \& Dev. 14: 1837-1851.

Rowley, J.D. 2001. Chromosome translocations: Dangerous liaisons revisited. Nat. Rev. Cancer 1: 245-250.

Schaeper, U., Gehring, N.H., Fuchs, K.P., Sachs, M., Kempkes, B., and Birchmeier, W. 2000. Coupling of Gab1 to c-Met, Grb2, and Shp2 mediates biological responses. J. Cell Biol. 149: 1419-1432.

Schwarz-Romond, T., Asbrand, C., Bakkers, J., Kuhl, M., Schaeffer, H.J., Huelsken, J., Behrens, J., Hammerschmidt, M., and Birchmeier, W. 2002. The ankyrin repeat protein Diversin recruits Casein kinase I $\varepsilon$ to the $\beta$-catenin degradation complex and acts in both canonical Wnt and Wnt/JNK signaling. Genes \& Dev. 16: 2073-2084.

Takeichi, M. 1995. Morphogenetic roles of classic cadherins. Curr. Opin.
Cell Biol. 7: 619-627.

Thiery, J.P. 2002. Epithelial-mesenchymal transitions in tumour progression. Nat. Rev. Cancer 2: 442-454.

Thompson, B., Townsley, F., Rosin-Arbesfeld, R., Musisi, H., and Bienz, M. 2002. A new nuclear component of the Wnt signalling pathway. Nat. Cell Biol. 4: 367-373.

Townsley, F.M., Thompson, B., and Bienz, M. 2004. Pygopus residues required for its binding to Legless are critical for transcription and development. J. Biol. Chem. 279: 5177-5183.

Willis, T.G., Zalcberg, I.R., Coignet, L.J., Wlodarska, I., Stul, M., Jadayel, D.M., Bastard, C., Treleaven, J.G., Catovsky, D., Silva, M.L., et al. 1998. Molecular cloning of translocation $\mathrm{t}(1 ; 14)(\mathrm{q} 21 ; \mathrm{q} 32)$ defines a novel gene (BCL9) at chromosome 1q21. Blood 91: 1873-1881. 


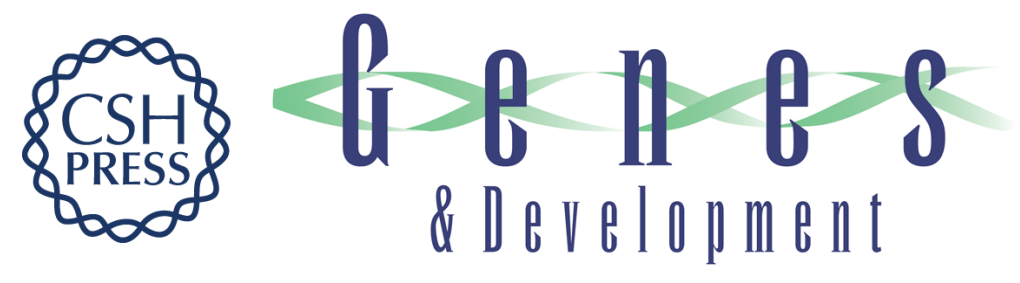

\section{Essential role of BCL9-2 in the switch between $\beta$-catenin's adhesive and transcriptional functions}

Felix H. Brembeck, Thomas Schwarz-Romond, Jeroen Bakkers, et al.

Genes Dev. 2004, 18:

Access the most recent version at doi:10.1101/gad.317604

References This article cites 36 articles, 15 of which can be accessed free at: http://genesdev.cshlp.org/content/18/18/2225.full.html\#ref-list-1

License

Email Alerting

Receive free email alerts when new articles cite this article - sign up in the box at the top Service right corner of the article or click here.

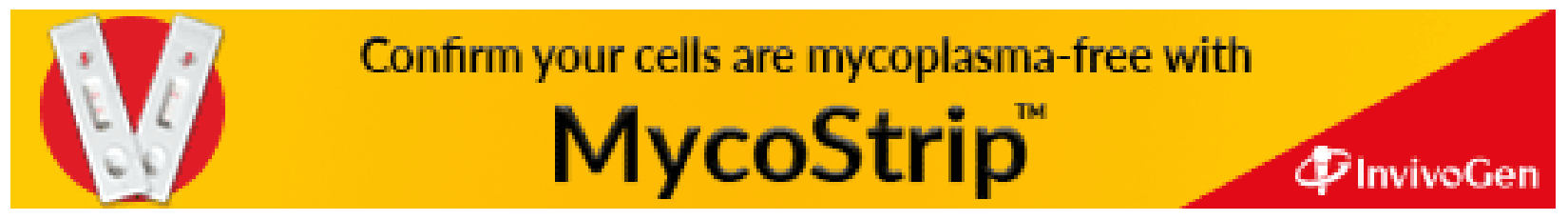

